\title{
COMO LEVAR O SUPREMO TRIBUNAL FEDERAL A SÉRIO: SOBRE A SUSPENSÃO DE TUTELA ANTECIPADA N. 9I
}

\author{
Vera Karam de Chueiri e Joanna Maria de Araújo Sampaio
}

HOW TO TAKE THE SUPREMO TRIBUNAL FEDERAL IBRAZILIAN FEDERAL SUPREME COURTI SERIOUSLY: ON THE SUSPENSION

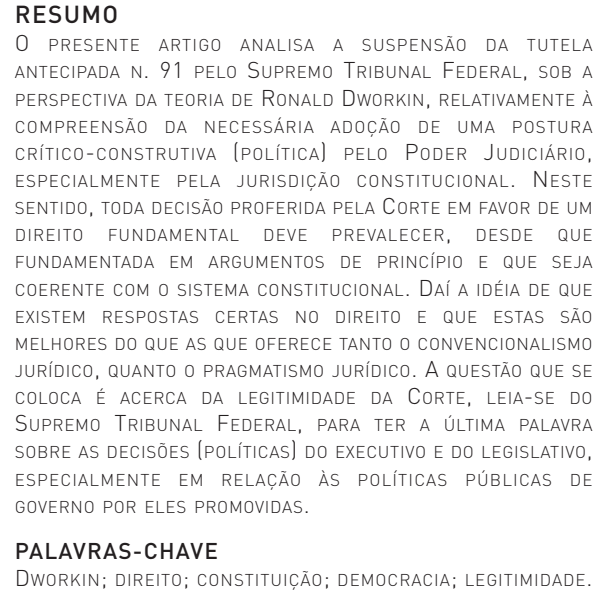

O PRESENTE ARTIGO ANALISA A SUSPENSÃo DA TUTELA antecipada n. 91 pelo Supremo Tribunal Federal, sob a PERSPECTIVA DA TEORIA DE RONALD DWORKIN, RELATIVAMENTE À COMPREENSÃO DA NECESSÁRIA ADOCC̄̃O DE UMA POSTURA CRÍtICO-CONSTRUTIVA (POLÍTICA) PELO PODER JUdICIÁRIO, ESPECIALMENTE PELA JURISDIC̄ÃO CONSTITUCIONAL. NESTE SENTIDO, TODA DECISÃO PROFERIDA PELA CORTE EM FAVOR DE UM DIREITO FUNDAMENTAL DEVE PREVALECER, DESDE QUE FUNDAMENTADA EM ARGUMENTOS DE PRINCÍPIO E QUE SEJA COERENTE COM O SISTEMA CONSTITUCIONAL. DAÍ A IDÉIA DE QUE EXISTEM RESPOSTAS CERTAS NO DIREITO E QUE ESTAS SÃO MELHORES DO QUE AS QUE OFERECE TANTO O CONVENCIONALISMO JURÍDICO, QUANTO O PRAGMATISMO JURÍDICO. A QUESTĀO QUE SE COLOCA É ACERCA DA LEGITIMIDADE DA CORTE, LEIA-SE DO Supremo Tribunal Federal, para ter a Última palavra SOBRE AS DECISÕES (POLÍTICAS) DO EXECUTIVO E DO LEGISLATIVO, ESPECIALMENTE EM RELAÇÃO ÀS POLÍTICAS PÚBLICAS DE GOVERNO POR ELES PROMOVIDAS.

PALAVRAS-CHAVE

DWORKIN; DIREITO; CONSTITUIC̣ÃO; DEMOCRACIA; LEGITIMIDADE.

\begin{abstract}
THIS ARTICLE AIMS AT ANALYZING THE SUSPENSION BY BRAZILIAN FEDERAL SUPREME COURT OF THE SUSPENSION OF ADVANCE CLAIM RIGHTS' CONCESSION N. 91 UNDER THE PERSPECTIVE OF RONALD DWORKIN'S THEORY, CONCERNING THE UNDERSTANDING THAT IT IS NECESSARY FOR JUDICIARY POWER TO HAVE A CRITICAL AND CONSTRUCTIVE (POLITICAL) ATTITUDE IN ORDER TO DECIDE ESPECIALLY FOR CONSTITUTIONAL COURTS. IN THIS SENSE, EVERY DECISION RENDERED BY THE COURT IN FAVOR OF A FUNDAMENTAL RIGHT MUST PREVAIL, ONCE IT IS FOUNDED ON ARGUMENTS OF PRINCIPLE AND IT IS COHERENT WITH THE CONSTITUTIONAL SYSTEM. THERE, IT FOLLOWS THE IDEA THAT THERE ARE RIGHT ANSWERS IN LAW AND THAT THESE ARE BETTER THAN THOSE OFFERED BY LEGAL CONVENTIONALISM OR LEGAL PRAGMATISM. THEN, IT ALSO FOLLOWS THE QUESTION ABOUT THE LEGITIMACY OF THE COURT, THAT IS, DOES THE SUPREMO TRIBUNAL FEDERAL SHOULD HAVE THE LAST WORD ON DECISIONS OF THE EXECUTIVE AND LEGISLATIVE POWERS, ESPECIALLY CONCERNING THEIR PUBLIC POLICIES?

KEYWORDS

DWORKIN; LAW; CONSTITUTION; DEMOCRACY; LEGITIMACY
\end{abstract}

\section{INTRODUÇÃO}

Embora o sistema jurídico constitucional brasileiro seja de tradição romano-germânica, do direito escrito, desde a promulgação da Constituição de 1988, ganhou força a leitura principiológica do nosso direito constitucional e, com isso, teorias da decisão judicial elaboradas com base na tradição anglo-americana, como a de Ronald Dworkin, provocaram novas reflexões acerca da jurisdição constitucional e, por conseguinte, 
novos argumentos paras as decisões da nossa corte, o Supremo Tribunal Federal ${ }^{1}$. Isto, que vimos chamando de leitura principiológica do direito, recolocou o poder judiciário, especialmente o STF, em cena não somente como aplicador do direito, mas como realizador de direitos. Isto, pois o STF, como corte constitucional, assumiu o papel de garantidor dos princípios constitucionais. Para muitas dessas concretizações de direitos ocorrerem, o judiciário precisou atuar de maneira mais incisiva, às vezes corrigindo a atividade dos demais poderes, como o executivo e o legislativo. No entanto, isso não transforma (e nem pode) o STF em uma espécie de legislador delegado ou algo que o valha.

Esta combinação de tradições (direito continental e common law) e, ainda, de um sistema jurídico-constitucional fortemente influenciado pelo positivismo de Kelsen pois coloca a norma jurídica no centro do sistema - e a abertura principiológica provocada pela Constituição de 1988 têm resultado em decisões judiciais inovadoras, porém, algumas de questionável fundamentação e que, assim, comprometem a coerência e a integridade do sistema constitucional. Tanto a dogmática constitucional como a jurisprudência mostram-se confusas, ao mesmo tempo em que procuram respeitar a Constituição - que impõe a efetivação dos princípios - descumprem o sentido dado aos princípios pela mesma, pois esta coloca os princípios como direitos fundamentais, e não como bens, que podem ser ponderados de acordo com a sua conveniência.

Por força dessa necessária reorganização da teoria constitucional, frente à posição de fundamentalidade dada aos princípios pela Constituição, ao analisar casos nos quais o judiciário impõe uma decisão contrária ao posicionamento do legislativo ou do executivo, remete-se à tensão entre o constitucionalismo e a democracia. Questiona-se até que ponto o Supremo Tribunal Federal, ao proteger os princípios constitucionais, poderia tomar decisões políticas diferentes das decisões tomadas pelos órgãos legislativo e executivo.

Dworkin oferece uma resposta a essas indagações. Analisando as possibilidades e os limites da prática judicial norte-americana, Dworkin resgata o desejo de construção de uma sociedade mais igualitária por meio de um direito que não se resume na legalidade, pois também possui uma dimensão moral e política. Mostra-nos que a aplicação do direito não é neutra ou apolítica. Os juízes não estão alheios ao processo de criação do direito, pois toda vez que o aplicam o constroem. Não no sentido defendido pelo positivismo que atribui aos juízes o poder discricionário de fazer o direito em casos em que este não se encontre disponível no sistema legal, mas, sim, no sentido de que os juízes podem e devem, com criatividade, buscar nos princípios o fundamento para suas decisões por meio da sua interpretação. Neste sentido, essa permanente construção do direito deveria ser realizada de maneira a melhor adequálo aos princípios constitucionais, em uma perspectiva passada, presente e futura.

Isto pode significar que uma determinada postura política do judiciário não permite que o juiz tome uma atitude passiva ao ver um direito ser violado. Os direitos 
devem ser levados a sério, na medida em que, apenas garantindo direitos morais mínimos aos cidadãos de uma nação, a coerção do direito se torna válida e o Estado Democrático de Direito em que vivemos pode assim ser significado.

Isso não quer dizer que o judiciário possa tomar o papel do legislador e tomar decisões sobre o melhor interesse da sociedade. Ao contrário, por não ser um órgão democrático - eleito pelo povo, não vitalício e responsável pelos seus atos - o judiciário apenas é legitimado para decidir de maneira a proteger os direitos individuais e sociais garantidos pela nossa Constituição.

Sem pretensões de igualar a prática constitucional norte-americana com a nossa, a teoria de Dworkin não só permite como pressupõe que seja analisada diferentemente de acordo com as distintas sociedades. Por pressupor um processo de conhecimento crítico-construtivo, segundo o qual construímos os significados de maneira a melhor se adaptarem à nossa realidade social e individual, sua teoria é aberta a alterações que a torne mais coerente com a cultura e história de uma sociedade. Pois bem, este artigo pretende analisar a suspensão da tutela antecipada n. 91, relativamente à demanda por meio da qual foi solicitadoo o fornecimento de medicamento ao Estado, tendo como marco teórico a jurisprudence de Ronald Dworkin e o seu compromisso com um sistema íntegro de direito que trate a todos com igual respeito e consideração.

\section{A SUSPENSÃo De TUTELA ANTECIPADA N. 9I : CONSIDERAÇões À LUZ DOS ARgumentos DE RONALD DWORKIN}

Dworkin adota a análise de casos concretos como metodologia para o estudo da prática judicial americana. Seguindo a mesma metodologia, foi escolhida demanda sobre pedido de fornecimento de medicamentos que não eram assegurados pelo Estado, necessários para garantir a vida e a saúde a pessoas que não poderiam pagar por eles de outra forma. Esse tipo de demanda, por meio de ação judicial, tem sido muito utilizada e envolve a polêmica constitucional dos limites do judiciário para interferir nas decisões do legislativo e do judiciário.

A suspensão de tutela antecipada n. 91, objeto de análise do presente artigo, trata de pedido do Estado de Alagoas para que suspendesse a liminar do Tribunal de Justiça de Alagoas, que determinou ao Estado de Alagoas o imediato fornecimento do tratamento necessário para pacientes renais crônicos em hemodiálise e pacientes transplantados.

O Estado de Alagoas alegou que a liminar geraria uma grave lesão à economia pública, pois o Estado não poderia ser obrigado a fornecer outros medicamentos além daqueles relacionados no Programa de Medicamentos Excepcionais e de alto custo. Ainda alegou a existência de grave lesão à ordem pública, pois o fornecimento de mais medicamentos que os previstos no referido programa inviabilizariam o fornecimento pelo Estado. 
Quando do julgamento da suspensão de tutela antecipada n. 91, a presidente do Supremo Tribunal Federal, na época a Ministra Ellen Gracie, suspendeu a liminar proferida pelo Tribunal de Justiça de Alagoas, sob o fundamento de que pelo direito à saúde, previsto na Constituição, o Estado deveria apresentar políticas públicas que atendessem a todos, e não a apenas uma minoria:

Entendo que a norma do art. 196 da Constituição da República, que assegura o direito à saúde, refere-se, em princípio, à efetivação de políticas públicas que alcancem a população como um todo, assegurando-lhe acesso universal e igualitário, e não a situações individualizadas. A responsabilidade do Estado em fornecer os recursos necessários à reabilitação da saúde de seus cidadãos não pode vir a inviabilizar o sistema público de saúde. (STF, STA 91/AL, rel. Min. Ellen Gracie, j. em 26.02.2007, DJ em 05.03.2007.)

Sob o ponto de vista da teoria da decisão judicial de Dworkin, a decisão da ministra estaria baseada em um argumento de política (policy), pois prefere uma promessa de bem comum à garantia do direito individual. Isto é, ao invés de recorrer a um princípio, cuja observância é uma questão de justiça, equidade ou qualquer outra dimensão da moral, a ministra preferiu fundamentar sua decisão, relativamente à demanda por medicamentos de pacientes renais crônicos em hemodiálise ou transplantados, em uma política pública, cuja observância é uma questão das possíveis vantagens (políticas, sociais e econômicas) que a sociedade, em geral, possa aferir. Ressalte-se que tanto o princípio quanto a política pública a que se referiu acima são espécies de norma constitucional.

\section{I ASPectos de Uma teoria dAS Decisões JUdiciais QUE SE BASEIA EM PRINCíPIOS}

Trata-se, pois, de um caso controverso, vale dizer, casos nos quais o juiz não conseguiria resolver por meio da simples aplicação da lei, isto é, da mera subsunção do fato concreto à norma geral e abstrata. Seriam "os casos em que nenhuma regra explícita no livro de regras decide com firmeza a favor de qualquer uma das partes" (DWORKIN, 2000, p. 10). Em tais situações, para se chegar à melhor resposta, há que se partir da distinção proposta por Dworkin entre princípios e (diretrizes) políticas, tendo em vista que mais coerente e consistente será a decisão para sustentar uma pretensão de direitos fundamentais, se baseada em princípios.

Para Dworkin, a prática judicial está associada a uma dimensão moral (DWORKIN, 2003, p. 3-4). Entretanto, direito e moral são diferentes e se sustentam em bases distintas. A presença de conteúdos morais no direito não significa uma moralização do direito (CHUEIRI, 2006, p. 181). Significa, sim, que o direito não pode ser neutro tanto em relação à moral quanto em relação à política e, conforme afirma Habermas, não basta que seu procedimento de normatização seja legal para que ele 
se torne legítimo (HABERMAS, 2003, p. 257). O direito só pode ser considerado válido enquanto for moralmente justificado, ou seja, se baseie em princípios, sendo o principal o da igualdade - segundo o qual todos devem ser tratados com igual respeito e consideração.

Dworkin afirma que "nenhum governo é legítimo a menos que demonstre igual consideração pelo destino de todos os cidadãos sobre os quais afirme seu domínio e reivindique fidelidade" (DWORKIN, 2005, p. IX). A igualdade seria dividida em dois princípios: o princípio da igual importância e o princípio da responsabilidade especial. O primeiro demandaria do governo uma adoção de leis e políticas que garantam que o destino dos cidadãos seja independente de quem eles sejam, de onde e sob que circunstâncias tenham nascido. O segundo exige que o governo respeite as opções de vida que os cidadãos fizerem, de acordo com a responsabilidade de cada um reger sua própria vida (DWORKIN, 2005, p. XVI-XVII). Assim, sua idéia de igualdade não dispensa a idéia de individualidade (no sentido da diferença), mas a integra, visto que o princípio da igualdade também abrange o igual respeito a todos os diferentes modos de vida.

Dworkin compromete a política com a moral na medida em que não acredita na existência de um contrato social original que deve nortear a atuação dos governantes. Para o autor, estes devem ter sua atuação política baseada em padrões éticos (GUEST, 1991, p. 7). O dever de igual consideração que os governantes devem ter ao criar as leis e elaborarem políticas públicas não deriva de um acordo ou consenso social, mas de valores éticos. Os governantes possuem liberdade para formular as leis e as políticas que acharem melhor para a sociedade, desde que não desrespeitem os princípios formulados pela moral social, em especial o da igual consideração por todos os cidadãos (DWORKIN, 2005, p. XIV-XV).

Essa ligação necessária entre política e moral compromete favoravelmente o exercício da jurisdição, pois a compreende como o locus de realização dos direitos fundamentais, pois, para Dworkin, os cidadãos possuem direitos individuais que devem ser preservados, independente do que os órgãos democráticos - não vitalícios e responsáveis por seus atos - acharem ser do interesse da sociedade. E ao poder judiciário é dado aplicar o direito no sentido da efetivação de tais direitos. Neste sentido, ele age moral e politicamente.

Dworkin afirma existirem duas concepções de Estado Democrático de Direito: a centrada no texto legal e a centrada nos direitos (DWORKIN, 2000, p. 6). A concepção centrada no texto legal admite que o Estado Democrático de Direito, para ser considerado como tal, deve assegurar aos seus cidadãos apenas os direitos expressamente previstos em lei. Assim, os juízes não deveriam decidir questões políticas, os direitos só deveriam ser garantidos se estivessem expressamente previstos na lei. O judiciário deveria fazer a seguinte pergunta: qual a vontade do parlamento ao aprovar essa lei? e não o que o parlamento deveria ter feito? 
Para a concepção centrada no texto legal, o juiz deveria tomar uma decisão perante os casos controversos de acordo com algumas "chaves" interpretativas, que lhe permitiria determinar a vontade do parlamento. A primeira é a semântica, segundo a qual se deve analisar qual a maior probabilidade da palavra ou termo que suscita dúvida ser utilizada para expressar determinada intenção. Ocorre que, muitas vezes, a palavra não expressa nenhuma decisão para o caso controverso.

A segunda é a de psicologia de grupo, que analisa declarações periféricas à lei, tais como audiências legislativas. No caso dos legisladores não terem pretendido responder a um caso específico, buscar-se-ia descobrir a intenção do parlamento caso fosse obrigado a decidir a questão. Mas qual seria o alcance desse método? Cartas ou conversas informais, por exemplo, seriam aceitas para formar a "provável” decisão? Essa "criação" de uma vontade latente do parlamento seria mais democrática do que uma decisão judicial fundada em princípio?

Dworkin afirma que:

Quando um juiz indaga o que os legisladores devem ter pretendido realizar, ele quer perguntar que políticas ou princípios ajustam-se mais naturalmente à lei que aprovaram. Quando indaga o que teriam feito se lhes exigissem que respondessem à pergunta que têm diante de si, quer perguntar que respostas decorrem das políticas ou princípios que se ajustam mais naturalmente à lei que aprovaram. Nenhuma questão é realmente psicológica ou histórica; todas colocam a mesma pergunta básica numa roupagem psicológica ou histórica (DWORKIN, 2000, p. 24-250).

Já para a concepção centrada nos direitos, para ser considerado como tal, o Estado Democrático de Direito não pode assegurar apenas os direitos prescritos nas leis. Por essa compreensão, o Estado Democrático de Direito deve assegurar igualmente os direitos morais que os cidadãos possuem entre si e os direitos políticos que eles possuem perante o Estado. A lei deve proteger e aplicar tais direitos, mas, se não o fizer, isso não impedirá que eles sejam impostos pelo Poder Judiciário em relação aos cidadãos individuais, "pois o ideal da prestação jurisdicional, no modelo centrado nos direitos, é de que, na medida em que isso é praticável, os direitos morais que os cidadãos efetivamente possuem devem ser acessíveis a eles no tribunal" (DWORKIN, 2000, p. 15).

Essa imposição pelo judiciário não seria arbitrária. As leis representam "as tentativas da comunidade para captar direitos morais e requer que qualquer princípio rejeitado nessas tentativas não tenha nenhum papel na prestação jurisdicional” (DWORKIN, 2000, p. 16).

Dworkin refuta as críticas aduzidas a essa imposição de direitos morais e políticos pelo Judiciário. O autor afirma que o Judiciário possui importante papel na defesa dos 
direitos das minorias, pois sofre menos pressões que os legisladores. Os legisladores sofrem pressões de grupos políticos fortes que podem impor sua vontade em detrimento de direitos individuais. Assim, "os legisladores não estão, institucionalmente, em melhor posição que os juízes para decidir questões sobre direitos" (DWORKIN, 2000, p. 27).

Alguns também objetam que os juízes não podem fazer julgamentos políticos, pois isso levaria a uma desordem social, uma vez que não há mecanismos de responsabilização do judiciário contra decisões impopulares. Assim, os cidadãos julgariam como ilegítimas as decisões proferidas pelos tribunais.

Todavia, para Dworkin, nos Estados Unidos:

[...] uma mudança na posição do Supremo Tribunal quanto à interpretação constitucional há algumas décadas - um deslocamento da confiança nos argumentos históricos para os argumentos políticos - não foi acompanhada por nenhuma perda séria no respeito do público pelas decisões do tribunal, tal como avaliada pela disposição do público a aquiescer (DWORKIN, 2000, p. 30).

O mesmo ocorre no Brasil, visto que a sociedade vem se adaptando a essa posição mais ativa ao resguardar os direitos fundamentais.

Por fim, Dworkin afirma que uma decisão do judiciário ao garantir direitos fundamentais não feriria a eqüidade. Pode-se questionar que uma postura política do judiciário diminuiria a igualdade de poder político dos cidadãos, pois estes elegem os legisladores que os representarão, e não os juízes. Ocorre que, em uma sociedade, os cidadãos não possuem uma verdadeira igualdade de poder político, há sempre grupos privilegiados que possuem maior influência sobre o legislativo. Por isso, a defesa de direitos mínimos individuais pode auxiliar para uma maior igualdade de poder político, na medida em que o judiciário não é tão influenciado pelos grupos dominantes como o legislativo.

Dworkin adota, então, a concepção de Estado Democrático de Direito centrada nos direitos. Sendo assim, o judiciário não pode estar alheio ao processo de construção e reconstrução do direito, deve sempre proteger os direitos individuais depreendidos do compromisso moral e político que a comunidade assumiu para se constituir como livre e igual. A efetividade dos direitos morais apenas se inicia com a elaboração das regras pelo executivo e pelo legislativo, é a atuação do judiciário que efetivará os direitos morais nos casos concretos. As regras gerais e abstratas necessitam ser aplicadas ao caso concreto, por isso os trabalhos de aplicação e de criação de regras e de políticas públicas são complementares. Não obstante serem complementares, deverão ser fundamentados diferentemente.

No mesmo sentido, Klaus Günther discorre sobre a diferença entre os discursos de aplicação (próprios do judiciário) e de justificação (próprios do legislativo e executivo), 
estes para se adequarem à moral social devem se manter afastados das particularidades concretas; já aqueles devem analisar essas mesmas particularidades para manterem morais as regras gerais e abstratas (CARVALHO, 2007, p. 10).

Günther analisa a relação entre moral e direito. Segundo o autor, a moral da sociedade seria responsável pela validade das normas, mas essa moral necessita ser aplicada, visto que, durante o processo de escolha dos valores adotados, os participantes do discurso público possuem conhecimento e tempo limitados, não conseguindo prever todas as hipóteses de aplicação de suas normas. Por isso, Günther diferencia os argumentos de justificação dos argumentos de aplicação.

Os argumentos de justificação seriam regidos pela universalidade, a qual pressupõe a imparcialidade tanto quanto às pessoas, quanto aos procedimentos. As normas devem ser justificadas pela universalidade, segundo a qual a sociedade proclama, por meio do discurso público, de maneira imparcial, seus valores e desejos. Nesse aspecto, há uma intensa relação entre o pensamento de Günther e o de Dworkin, na medida em que este afirma que os argumentos de política devem representar os valores da comunidade política com igual respeito e consideração (GÜNTHER, 2004, p. 412).

Já os argumentos de aplicação seriam regidos pela coerência, de maneira a efetivar a imparcialidade. A aplicação só será imparcial quando for coerente, isto é, se adequar a todas as características de uma situação, de maneira a tratar igualmente casos iguais, tendo em vista não apenas a norma isolada, mas a pluralidade de situações que gravitam ao seu redor.Também nesse aspecto, há semelhança com o pensamento de Dworkin em relação aos argumentos de princípios. Para Dworkin, também existe a necessidade do juiz, ao aplicar o caso concreto, se mostrar coerente não apenas em relação às normas do sistema jurídico, mas essencialmente em relação aos princípios erigidos pela comunidade política (GÜNTHER, 2004, p. 414).

Não há, pois, que se falar em discricionariedade no sentido (do positivismo de Hart) de que o juiz, em face de um caso controverso, cria o direito, na medida em que a ele é dado interpretar o conjunto de práticas que significam o direito como os precedentes, a legislação e os padrões morais socialmente compartilhados e, a partir deles, construir a sua decisão baseada no princípio que melhor descreva essas práticas.

$\mathrm{Na}$ esteira da sua teoria da resposta certa, toda demanda judicial possui uma resposta, devendo ela ser construída de maneira coerente, pela escolha do princípio aplicável ao caso. Não qualquer princípio, mas aquele que aplicado ao caso o faça à luz do compromisso assumido de que todos devem ser tratados com igual respeito e consideração. Assim, o juiz, ao decidir o caso controverso, deverá interpretar os argumentos apresentados, levando em consideração não só as regras e os precedentes, mas também os padrões morais da sociedade e os seus próprios.

Para Dworkin, o direito deve ser concebido em cadeia (the chain of Law), como uma narrativa, na qual cada decisão construída acrescenta um capítulo na história das práticas que o significam. Como narrativa, ele se reconstrói a cada decisão, mas 
observando a coerência destas relativamente ao compromisso de tratar a todos com igual respeito e consideração.

Os princípios são normas cujas exigências morais devem vincular tanto o legislativo quanto o judiciário. Para o autor, o direito não pode ser reduzido a regras, pois estas não encerram o debate sobre a efetivação do direito, apenas o iniciam, já que, por seu caráter geral e abstrato, elas não conseguiriam regular a sua própria aplicação (CARVALHO, 2007, p. 9). O aplicador do direito possui uma função distinta do legislador, na medida em que promoverá a concretude dos direitos, aplicando-os em face do caso real.

Parece estranho que o positivismo jurídico, - o qual limita a decisão judicial à simples aplicação das regras -, possa permitir uma atuação discricionária do juiz, aceitando que ele, em certos casos, decida como entender melhor. Mas a idéia positivista de reduzir o direito às regras, sendo que os direitos individuais seriam apenas backgroundrights para a aplicação das mesmas, resultaria em dois resultados distintos: de um lado, o juiz simplesmente aplicaria a lei ao caso, sem maiores questionamentos; de outro, em caso de uma lacuna na lei, o juiz deveria "descobrir" (discricionariamente) o direito aplicável ao caso.

Dworkin refuta essa idéia, pois, para ele, o direito não seria um sistema fechado de regras. $\mathrm{O}$ autor adota um sistema aberto de regras, dessa maneira, o direito permitiria a possibilidade de criticá-lo internamente, pois os direitos morais sairiam do seu exílio como background rights e passariam a influenciar a interpretação das regras, inclusive para a solução dos casos difíceis (CHUEIRI, 1995, p. 86). Assim, o juiz não precisaria criar um direito para decidir um caso difícil. Ele responderia ao caso com fundamento nos princípios constitucionais, o que afirma o caráter institucional de tais direitos. Desta forma, os juízes não podem se esquivar de tomar decisões para as quais não exista uma regra clara, mas as suas decisões não podem ser arbitrárias, isto é, elas não podem ser tomadas sem um fundamento (em princípios).

Para Dworkin, os argumentos de política e de princípio se distinguem da seguinte maneira: os argumentos de política justificam a decisão, mostrando que ela protegeria um objetivo coletivo, da comunidade inteira, já os argumentos de princípio mostram que a decisão protege um direito individual ou de um grupo específico (DWORKIN, 2002, p. 129). Os princípios descreveriam direitos, enquanto as políticas descreveriam objetivos. O objetivo político seria uma justificação política genérica (DWORKIN, 2002, p. 142), já o direito seria o objetivo individualizado.

A decisão da Ministra Ellen Gracie, analisada mais à frente, foi no sentido de que o direito individual à saúde não deveria ser protegido em prejuízo do direito coletivo à saúde. Então, de acordo com Dworkin, seu argumento seria de política, pois sua decisão protegeria um objetivo coletivo, e não um direito individual. Nesse aspecto, a decisão da ministra foi, estruturalmente, pragmática, pois decidiu de modo a melhor atender aos interesses da coletividade em detrimento do direito demandado. 
Assim, visando atender aos interesses da coletividade, podemos notar que a ministra se vale de um argumento econômico ao afirmar que o direito de muitos não pode ser prejudicado pelo direito de um indivíduo. Para Dworkin, os argumentos econômicos caracterizam não só uma adoção de políticas como também ferem a igualdade:

[...] o Tribunal deve tomar decisões de princípio, não de política - decisões sobre que direitos as pessoas têm sob nosso sistema constitucional, não decisões sobre como se promove o bem-estar geral -, e que deve tomar essas decisões elaborando e aplicando a teoria substantiva da representação, extraída do princípio básico de que o governo deve tratar as pessoas como iguais (DWORKIN, 2002, p. 154).

\section{PosSibilidides INTER PRETATIVAS PARA AS PRÁticas JURÍdiCAS: CONVENCIONALISMO, PRAGMATISMO E DIREITO COMO INTEGRIDADE}

\section{2. i Convencionalismo e PRAgmatismo}

Dworkin afirma que existem diferentes maneiras de interpretar abstratamente a prática jurídica. Ele as divide em três concepções de direito: o convencionalismo, o pragmatismo jurídico e o direito como integridade (DWORKIN, 2003, p. 118).

O convencionalismo acredita que a prática jurídica é uma questão apenas de aplicação das convenções jurídicas, que seriam as convenções sociais, as quais garantiriam à constituição, à lei e aos precedentes judiciais uma posição impositiva. Para essa concepção, nos casos difíceis, em que nenhuma convenção se enquadre ao caso, os juízes deveriam decidir da melhor forma possível, isto é, discricionariamente, utilizando padrões extrajurídicos. Assim, o juiz criaria um novo direito, que se transformaria em um precedente, isto é, adquirindo poder coercitivo (DWORKIN, 2003, p. 143-145).

Excetuando-se essa hipótese de discricionariedade para a decisão de um caso difícil, a atividade dos juízes é totalmente vinculada. Se existe uma decisão aprovada por uma convenção, o juiz deve acatá-la, mesmo que acredite que ela violaria os princípios jurídicos, já que estes só adentrariam o direito se fossem protegidos por uma convenção.

Dessa maneira, o convencionalismo procura encontrar o equilíbrio entre previsibilidade e flexibilidade. Quando a convenção for clara e explícita, o juiz deverá aplicá-la totalmente, privilegiando a previsibilidade. Já quando a convenção for omissa ou implícita, o juiz privilegiará a flexibilidade, decidindo como achar melhor (DWORKIN, 2003, p. 179).

O pragmatismo se opõe a esse equilíbrio da maneira pregada pelo convencionalismo. Para o pragmatismo, os indivíduos não têm direito a nada, o juiz deverá analisar que decisão será melhor para a coletividade. Se privilegiar a previsibilidade for o melhor para toda a comunidade, a convenção deverá ser adotada, mas, se outro 
entendimento for mais proveitoso para a comunidade que a garantia da previsibilidade, este entendimento deve ser adotado, independente da convenção.

Apesar de parecer mais imprevisível que o convencionalismo, o pragmatismo, nos casos difíceis, pode oferecer mais segurança, pois estes não serão decididos discricionariamente pelo juiz. Isso ocorre porque, pelo pragmatismo, o juiz deverá sempre buscar a solução que mais se ajustaria ao interesse da comunidade. Assim, esta fixação de uma linha de pensamento a ser seguida pelo juiz torna as decisões pragmáticas nos casos controversos mais fáceis de serem previstas do que as convencionais.

O pragmatismo, em comparação com o convencionalismo, é uma posição que explica melhor a prática jurisprudencial americana, mas ele não reconhece os princípios como fundamentais à atividade jurisdicional. Dworkin refuta o pragmatismo e explica a sua concepção do direito como integridade.

Nesse sentido, a Ministra Ellen Gracie, ao conferir a suspensão de tutela antecipada n. 91, decidiu por proteger o que entendeu ser o melhor para a coletividade. Nota-se que sua decisão foi de caráter utilitário-pragmático, pois suprimiu o direito individual à saúde em nome do interesse da coletividade. Entretanto, sublinhe-se que, se o resultado da decisão da ministra fosse, ao contrário, a concessão da tutela pretendida, porém com base em uma fundamentação igualmente utilitário-pragmática, estar-se-ia diante de uma decisão igualmente criticável ou objetável. Isto, pois, a medida de uma decisão judicial coerente e íntegra não está exatamente no seu resultado, mas na construção e na força do seu argumento. Aliás, pautar a decisão pelo seu resultado ou do que seria melhor para a comunidade no futuro significa admitir que à justiça, no caso concreto, precede uma lógica consequencialista, da melhor conveniência, a qual eufemisticamente se denomina de bem comum.

\subsection{Direito Como InTEgridade}

Para compreender melhor a teoria da decisão de Dworkin se faz necessário analisar o significado da sua concepção do direito como integridade.

A integridade política de Dworkin se divide em dois princípios: o legislativo, que consiste na exigência de que as leis sejam, na medida do possível, coerentes com a moral da comunidade; e o jurisdicional, que consiste na exigência de que as decisões judiciais tentem analisar as leis como sendo moralmente coerentes.

Os pragmáticos contestam a integridade política, pois, para eles, a comunidade não seria uma entidade distinta, com uma vontade própria. Mas afirma o autor que a integridade não pressupõe uma entidade distinta de seus cidadãos, ao contrário, pressupõe uma interligação entre os cidadãos e a comunidade.

A integridade realiza uma interpenetração entre o público e o privado. As leis não são apenas acordos entre os cidadãos para alcançarem uma experiência social pacífica. As leis devem representar a moralidade compartilhada entre os membros de uma comunidade. Assim, a legitimidade política, a possibilidade de um direito coercitivo, 
derivaria de uma fidelidade dos cidadãos aos princípios da comunidade, que seriam representativos de seus padrões morais (DWORKIN, 2003, p. 230).

Dworkin relaciona a integridade com a fraternidade almejada pela revolução francesa. Ele afirma que o dever de respeitar as leis é proveniente de uma fraternidade social semelhante à de uma família ou grupo de amigos. Essa comunidade, regida pelo ideal de fraternidade, seria a comunidade de princípios.

A comunidade de princípios é uma comunidade moralmente plural, ou seja, ela procura uma integridade entre os diversos valores morais, respeitando igualmente a moral de todos os cidadãos. Ela adota um compromisso com os seus princípios e os manifesta na elaboração das políticas por meio da legislação e na sua aplicação pelo judiciário nas decisões judiciais.

Dworkin ressalta que a integridade, por ser um valor independente da justiça e da eqüidade, não exige que as concepções da comunidade sejam efetivamente justas e eqüitativas, ela apenas fornece uma justificação política, unindo-a com a moral da comunidade (DWORKIN, 2003, p. 257).

Analisando a integridade do ponto de vista jurisdicional, da aplicação das decisões políticas, os juízes deveriam interpretar o direito como sendo criado por um único ator, a comunidade personificada (DWORKIN, 2003, p. 271-272). Este autor construiria o direito com base em uma noção própria e coerente de justiça e eqüidade. Dessa forma, não bastaria analisar o direito como um processo histórico, ou apenas contemporâneo. É necessário interpretá-lo de maneira que a história jurídica seja coerente com o presente e com o futuro:

O direito como integridade, portanto, começa no presente e só se volta para o passado na medida em que seu enfoque contemporâneo assim o determine. Não pretende recuperar, mesmo para o direito atual, os ideais ou objetivos práticos dos políticos que primeiro o criaram. Pretende, sim, justificar o que eles fizeram (às vezes, incluindo, como veremos, o que disseram) em uma história geral digna de ser contada aqui, uma história que traz consigo uma afirmação complexa: a de que a prática atual pode ser organizada por princípios suficientemente atraentes para oferecer um futuro honrado (DWORKIN, 2003, p. 274).

Para compreender sua teoria do direito como integridade, Dworkin faz uma analogia com o processo de criação literária. Para ele, o direito como integridade pode ser exemplificado por um romance em cadeia, no qual vários autores escrevem um romance em conjunto. O romance deve ficar o mais coerente possível e os autores devem pensar em qual interpretação daria maior significado tanto ao que já foi escrito, quanto ao que será escrito. Portanto, ao continuar a "obra" do autor anterior, o autor atual deverá analisar toda a história do romance e escrever de maneira a possibilitar que as 
aspirações da obra possam ser melhor escritas no futuro. Com isso, Dworkin mostra que não se pode escrever um romance sem esquecer o caminho trilhado no passado, mas, se não se perceber os seus objetivos futuros, ele poderá tomar outros rumos.

Mesmo admitindo que tal romance provavelmente ficará ruim, Dworkin afirma que, apesar de terem essa consciência, o dever dos autores é escrevê-lo da melhor maneira possível, devendo o romance possuir ao menos um mínimo de coerência, isto é, deve ser guiado por uma série de princípios que permearão a obra.

Os juízes, ao decidirem um caso, deverão fazê-lo de maneira equânime, os princípios deverão ser aplicados à solução de todos os casos igualmente, mas isso não quer dizer que os juízes devam se fechar nos precedentes, suas decisões devem se adequar aos princípios expressos ou não pela constituição: "O direito como integridade não se limita ao conteúdo explícito das decisões coletivas passadas, mas reclama os princípios que a elas se ajustam e as justificam” (CHUEIRI, 1995, p. 130).

Diferente do convencionalismo, os juízes, nos casos difíceis, terão suas decisões limitadas estruturalmente pelo sistema de princípios, mas estes não podem ser vistos de maneira estática. O juiz “[...] deve considerar provisórios quaisquer princípios ou métodos empíricos gerais que tenha seguido no passado, mostrando-se disposto a abandoná-los em favor de uma análise mais sofisticada e profunda quando a ocasião assim o exigir" (DWORKIN, 2003, p. 308).

Dworkin afirma que o direito como integridade não fornece respostas às questões. Nem mesmo as respostas de Hércules (juiz criado por Dworkin com capacidades sobre-humanas e que acredita no direito como integridade) seriam as verdadeiras de acordo com o conceito de integridade:

Mas o direito como integridade consiste numa abordagem, em perguntas mais que em respostas, e outros juristas e juízes que o aceitam dariam respostas diferentes das dele às perguntas colocadas por essa concepção de direito. [...] Se você rejeitar esses pontos de vista distintos por considerá-los pobres enquanto interpretações construtivas da prática jurídica, não terá rejeitado o direito como integridade: pelo contrário, ter-se-á unido a sua causa (DWORKIN, 2003, p. 287).

Se um juiz aceita a justiça como integridade, deve verificar qual decisão a prejudica menos. Isso não quer dizer que os juízes devam se vincular aos precedentes, mas devem decidir de maneira que todos sejam julgados pelos mesmos parâmetros de justiça.

Normalmente, a decisão deverá ser a que melhor se adapte ao sistema de princípios constitucionais integralizados pela comunidade. Isso se torna mais claro quando o juiz decide com base em decisões precedentes. Na referida decisão da Ministra Ellen Gracie, tem-se que esta rompeu com os precedentes, visto que, como 
será demonstrado abaixo, o direito fundamental à saúde é aplicado uniformemente pela jurisprudência nacional.

O direito como integridade de Dworkin não exige uma estrita observação aos precedentes. Dworkin analisa qual a força gravitacional de um precedente. Ele chega à conclusão que esta força gravitacional - de fazer com que os outros casos semelhantes ao precedente sejam resolvidos da mesma maneira - só existirá se o argumento do precedente for um argumento de princípio, e não quando for um argumento de política. Assim, se Hércules concluir que existe a força gravitacional do precedente, ele não deverá decidir de maneira diversa. Isso porque "[...] o direito pode não ser uma trama inconsútil, mas o demandante tem o direito de pedir a Hércules que o trate como se fosse." (DWORKIN, 2002, p. 182). Desta forma, Hércules deverá:

[...] construir um esquema de princípios abstratos e concretos que forneça uma justificação coerente a todos os precedentes do direito costumeiro e, na medida em que estes devem ser justificados por princípios, também um esquema que justifique as disposições constitucionais e legislativas

(DWORKIN, 2002, p. 182).

Defende o autor que a decisão deverá ser coerente verticalmente, isto é, por princípios que fornecem a justificação das estâncias mais elevadas, e horizontalmente, por princípios que forneçam a justificação a decisões do mesmo nível. A ordenação vertical nos Estados Unidos seria: primeiro, a constituição; segundo, a Suprema Corte; terceiro, as leis promulgadas pelos órgãos legislativos; e quarto, as decisões dos demais tribunais. Essa ordenação vertical delimitará a atuação das esferas inferiores, mas Hércules pode discordar da opinião sobre determinada norma e acreditar em outra justificação para uma questão. Essa opinião de Hércules terá um impacto na estrutura de justificativas dos demais tribunais.

Com efeito, a ministra não precisaria decidir conforme a jurisprudência dominante, mas, para isso, a sua decisão, que deve sempre ser baseada em um argumento de princípio, deve fornecer uma justificação que se integre melhor ao sistema constitucional, ou seja, deve fornecer melhor continuação para o romance que está sendo escrito. É o que será analisado a seguir.

\section{Decisões anteriores e Posteriores (À SUSPENSÃo DE TUTEla ANTECIPADA N. 9I)}

As decisões judiciais desde a promulgação da Constituição de 1988 têm, majoritariamente, garantido o direito individual à saúde aos que necessitam de tratamento médico, urgente e de custo elevado para seus padrões financeiros, mas que não estão albergados pelas políticas públicas de saúde. O Supremo Tribunal Federal, especialmente, tem 
assim se manifestado, a exemplo, a decisão do Ministro Celso de Mello, julgada em janeiro de 1997:

A singularidade do caso (menor impúbere portador de doença rara denominada Distrofia Muscular de Duchene), a imprescindibilidade da medida cautelar concedida pelo poder Judiciário do Estado de Santa Catarina (necessidade de transplante das células mioblásticas, que constitui o único meio capaz de salvar a vida do paciente) e a impostergabilidade do cumprimento do dever político-constitucional que se impõe ao Poder Público, em todas as dimensões da organização federativa, de assegurar a todos a proteção à saúde (CF, art. 196) e de dispensar especial tutela à criança e ao adolescente (CF, art. $6^{\circ}, \mathrm{c} / \mathrm{c}$ art. $227, \S 1^{\circ}$ ) constituem fatores, que, associados a um imperativo de solidariedade humana, desautorizam o deferimento do pedido ora formulado pelo Estado de Santa Catarina (fls. 2/30). [...] Entre proteger a inviolabilidade do direito à vida, que se qualifica como direito subjetivo inalienável assegurado pela própria Constituição da República (art. $5^{\circ}$, caput), ou fazer prevalecer, contra essa prerrogativa fundamental, um interesse financeiro e secundário do Estado, entendo - uma vez configurado esse dilema - que razões de ordem éticojurídica impõem ao julgador uma só e possível opção: o respeito indeclinável à vida. Por tal motivo, indefiro o pedido formulado pelo Estado de Santa Catarina, pois a decisão proferida pela Magistratura catarinense - longe de caracterizar ameaça à ordem pública e administrativa local, como pretende o Governo estadual (fls. 29) - traduz, no caso em análise, um gesto digno de reverente e solidário apreço à vida de um menor, que, pertencente a família pobre, não dispõe de condições para custear as despesas do único tratamento médico-hospitalar capaz de salvá-lo de morte inevitável (fls. 76). (STF, PETMC n. 1.246/SC, rel. Min. Celso de Mello, j. em 31.1.1997)

Verifica-se que o caso, embora semelhante à suspensão de tutela antecipada $n$. 91, foi decidido de maneira muito diversa pela ministra Ellen Gracie. O ministro Celso de Mello decidiu por proteger o direito individual à saúde ${ }^{2}$. Ao se eximir de proferir uma decisão fundada em um argumento econômico ou político, o ministro privilegiou o princípio da vida digna, protegendo o direito individual à saúde, ainda que seu argumento não manifeste expressamente a adesão a uma dada teoria das decisões judiciais como a de Dworkin.

De toda forma, pode-se dizer que a posição do ministro mostra-se coerente com a perspectiva de Dworkin, principalmente quando ele afirma que, entre proteger o direito à vida ou um interesse financeiro do Estado, "[...] razões de ordem ético-jurídica impõem ao julgador uma só e possível opção: o respeito indeclinável à vida”. 
Neste trecho, fica claro que o ministro Celso de Mello levou os direitos a sério, pois admitiu que os princípios são imponderáveis e devem ser respeitados, não devendo o juiz decidir de maneira utilitarista, colocando o interesse coletivo acima dos direitos individuais.

O tema vem sendo decidido nos mesmos moldes pelos tribunais inferiores ${ }^{3}$. Os tribunais regionais federais também são notadamente favoráveis à imposição do Estado ao cumprimento dos princípios constitucionais, fundamentando suas decisões também com base em argumento de princípio.

Da mesma maneira que as decisões anteriores, as decisões posteriores à suspensão de tutela antecipada n. 91 se mantiveram no sentido de garantir o direito individual à saúde.

Em recente decisão, o STJ, tendo como relatora a ministra Eliana Calmon, afirmou que o direito à vida e à saúde devem ser protegidos como bens máximos erigidos pela Constituição. Assim, independentemente das políticas públicas realizadas pelo Estado, o judiciário não poderia se manter inerte frente à uma violação aos princípios constitucionais.

[...] 4. Embora venha o STF adotando a "Teoria da Reserva do Possível" em algumas hipóteses, em matéria de preservação dos direitos à vida e à saúde, aquela Corte não aplica tal entendimento, por considerar que ambos são bens máximos e impossíveis de ter sua proteção postergada. (STJ, REsp n.

835.687/RS, rel. Min. Eliana Calmon, $2^{\mathrm{a}}$ T., DJ de 17.12.2007.)

Mas, apesar de pretender adotar uma postura principiológica, a decisão da ministra Eliana Calmon confunde princípios com bens. Essa confusão distorce a importância que os princípios devem possuir dentro do ordenamento jurídico e principalmente seu caráter vinculante da decisão judicial. Diferentemente dos bens jurídicos, os princípios não podem ser ponderados, eles devem ser totalmente aplicados pelo juiz, conforme o conceito de direito como integridade. Embora tentasse proteger o direito individual à vida e à saúde, a ministra o relega à posição de bens, retirando o seu caráter impositivo.

A decisão do ministro Luiz Fux é mais coerente, pois afirma que o judiciário deve sempre se guiar pelos princípios, e não por políticas, de maneira a não compactuar com as decisões dos órgãos democráticos que firam os direitos individuais.

[...] 8. Os direitos fundamentais à vida e à saúde são direitos subjetivos inalienáveis, constitucionalmente consagrados, cujo primado, em um Estado Democrático de Direito como o nosso, que reserva especial proteção à dignidade da pessoa humana, há de superar quaisquer espécies de restrições legais. [...] 9. A Constituição não é ornamental, não se resume a um museu de 
princípios, não é meramente um ideário; reclama efetividade real de suas normas. Destarte, na aplicação das normas constitucionais, a exegese deve partir dos princípios fundamentais, para os princípios setoriais. E, sob esse ângulo, merece destaque o princípio fundante da República que destina especial proteção a dignidade da pessoa humana. 10. Outrossim, a tutela jurisdicional para ser efetiva deve dar ao lesado resultado prático equivalente ao que obteria se a prestação fosse cumprida voluntariamente. O meio de coerção tem validade quando capaz de subjugar a recalcitrância do devedor. O Poder Judiciário não deve compactuar com o proceder do Estado, que condenado pela urgência da situação a entregar medicamentos imprescindíveis proteção da saúde e da vida de cidadão necessitado, revela-se indiferente à tutela judicial deferida e aos valores fundamentais por ele eclipsados [...].

(STJ, Resp n. 2006.00.674080/RS, 1ªT., rel. Min. Luiz Fux, j. em 08.05.2007, DJ de 31.05.2007.)

Ao afirmar que a constituição exige efetividade, e que esta deverá ser realizada por meio de seus princípios, o ministro mostra que não basta a elaboração de normas gerais e abstratas. A efetividade dos direitos apenas se inicia com o processo legislativo de criação de normas, necessitando, para se concluir, da atuação do judiciário na aplicação dos direitos. Para esta aplicação, o judiciário deverá ter como base não somente as regras, mas especialmente os princípios, os quais deverão ser respeitados sempre, mesmo não existindo uma regra clara para o caso.

\section{A Última decisão: o STF e a CONCRetização DOS PRINCÍPIOS CONSTITUCIONAIS}

A adoção de argumentos de política por parte do judiciário ainda é muito freqüente em uma sociedade como a brasileira, que possui recente história constitucional democrática. Por termos uma democracia débil, com ausência de debates públicos e poucas manifestações populares para reivindicar seus direitos, o judiciário é um grande fórum de debate. Ocorre que este fórum se torna usurpador de poderes do legislativo e do executivo no momento em que os julgadores decidem com base em argumentos de política.

Dentro do judiciário, são manifestados inúmeros argumentos morais e políticos que influenciam o juiz na sua decisão. Mas o juiz, ao interpretar esses argumentos, não pode tomar posição de legislador e decidir qual é o melhor interesse da maioria para o caso. Os argumentos políticos só são legítimos para os poderes executivo e legislativo, pois, como representantes da maioria, podem decidir o que seria melhor para ela. Ao judiciário cabe aplicar coerentemente as normas - em uma acepção aberta, a qual compreende regras e princípios -, para isso, deve se fundamentar em 
um argumento de princípio, isto é, deve garantir que, na aplicação de uma norma ou política pública, nenhum princípio eleito pela constituição seja descumprido.

Essa responsabilidade do judiciário em proteger os direitos individuais nos casos concretos, muitas vezes, é ignorada por nossa corte constitucional, que acaba por usurpar o papel do legislador e decidir o que seria melhor para a maioria no caso e não qual seria a melhor decisão para aquele caso específico, respeitando os princípios do igual respeito e consideração e da liberdade.

Essa adoção de argumentos políticos por nossa corte constitucional pode ser claramente exemplificada pela decisão da ministra Ellen Gracie na suspensão de tutela antecipada n. 91. Em sua decisão, a Ministra ignora o direito individual ao medicamento, não protegendo o direito à vida e à saúde no caso, para adotar um argumento político. Filiando-se a um pragmatismo jurídico - segundo o qual os cidadãos não possuem direitos e, assim, os juízes devem decidir da maneira que melhor atender os interesses da coletividade - a ministra decide que "[...] a norma do art. 196 da Constituição da República, que assegura o direito à saúde, refere-se, em princípio, à efetivação de políticas públicas que alcancem a população como um todo, assegurando-lhe acesso universal e igualitário, e não a situações individualizadas" (STF, STA 91/AL, rel. Min. Ellen Gracie, j. em 26.02.2007, DJ em 05.03.2007.). Dessa maneira, o direito individual poderia ser sacrificado para atender a um interesse coletivo.

Sob outro ponto de vista, apesar da nossa Constituição de 1988 ser marcada por um forte caráter principiológico, nossa prática constitucional ainda confunde reiteradamente princípios com valores. É o que foi mostrado na decisão da ministra Eliana Calmon, que, ao garantir o direito à vida e à saúde, não os garante como princípios imponderáveis e de normatividade obrigatória. Para a ministra, o direito à vida e à saúde são vistos como "bens máximos" (STJ, REsp n. 835.687/RS, rel. Min. Eliana Calmon, $2^{a}$ T., DJ de 17.12.2007), e como tais, em diferentes circunstâncias, poderiam ser sopesados frente a outros interesses.

A Constituição de 1988 trouxe, como resultado de um processo histórico de desenvolvimento do constitucionalismo brasileiro, uma tradução principiológica de seu conteúdo. Entretanto, o seu caráter principiológico foi traduzido em um caráter valorativo, por meio da aderência pelo constitucionalismo brasileiro à doutrina de Robert Alexy ${ }^{4}$, na qual a constituição seria uma ordem concreta de valores. Segundo a teoria de Alexy, uma das diferenças entre princípios e regras é que, em casos de conflitos entre estas, deve-se aplicar integralmente a regra que mais se conforma ao caso, isso porque elas seriam definitivas, ou são aplicadas integralmente ou não são aplicadas; já no caso de conflitos entre princípios, eles poderiam ser ponderados, sendo permitido que, dependendo dos interesses relativos ao caso concreto, algum princípio seja aplicado parcialmente, pois possuem apenas uma exigência abstrata. Desta maneira, a Constituição admitiria, por meio de uma disputa argumentativa, que seus princípios - lidos como valores - fossem ponderados conforme os interesses em jogo 
no caso concreto (CHUEIRI, 2008). Não obstante a teoria da argumentação de Alexy tenha sido recepcionada pelo direito constitucional brasileiro - não sem a influência dos scholars portugueses como Canotilho - e, da mesma forma, siga como principal referência das decisões constitucionais que se fundamentam em princípios e, assim, se valem da metodologia da ponderação, isso não quer dizer que o significado da constituição depende ou se encerra em tal teoria. Ao contrário, a compreensão e, com ela, o significado da constituição se dão pela singularidade do contexto de aplicação, no qual os princípios (que são normas) e, mais especialmente, o princípio segundo o qual todos devem ser tratados com igual respeito e consideração, sem mitigação e, por conta da sua importância, sustentará a pretensão de direito que se quer que prevaleça.

Dworkin admite uma interpretação construtiva da constituição. Na medida em que ela é criada por meio de um debate político, ela não pode ser lida como neutra do ponto de vista moral e político. A sua interpretação deve construí-la e reconstruíla no tempo e no espaço, de maneira a sempre torná-la a melhor possível - isto é, de modo a sempre estar de acordo com os compromissos democráticos e republicanos que resultaram na sua elaboração.

Nos casos controversos - nos quais normalmente estarão envolvidos princípios uma análise valorativa da constituição fere a democracia e carece de legitimidade, pois a ponderação dos interesses em questão é uma decisão a ser tomada pelos órgãos eleitos democraticamente. A esses órgãos, eleitos por meio desta tensão entre as diferentes esferas de poder que existem em uma sociedade, cabe decidir de maneira a representar a maioria que o elegeu - ainda que devam estar comprometidos com os princípios.

A legitimidade e a autoridade do direito estão na sua coerência com os compromissos públicos que os princípios representam. Assim, o judiciário deve proteger os direitos fundamentais garantidos na constituição, valendo-se, para decidir, de um argumento de princípio. Os princípios, para Dworkin, são normas assim como as regras e, da mesma maneira, devem ser aplicados integralmente, sendo incabível ao judiciário sopesar qual interesse deve prevalecer no caso concreto. Assim, segundo a teoria da resposta certa de Dworkin, o judiciário deve decidir da melhor maneira, analisando qual seria a decisão mais coerente possível frente ao sistema principiológico constitucional.

Dessa maneira, o papel do judiciário é de suma importância, pois ele é responsável, por meio de suas decisões, por reafirmar e reconstruir o significado da constituição toda vez que aplicá-la ao caso concreto.

Nos casos de fornecimento de medicamentos de alto custo às pessoas com baixo poder aquisitivo, no qual estão em jogo não só o direito à saúde, mas o direito à vida, a jurisprudência tem sido generosa no sentido de aplicar os princípios constitucionais e, por meio destes, conceder o direito pretendido, ainda que os argumentos das decisões insistam, na maioria dos casos, em confundir princípios com valores. 
Tanto melhor seriam as decisões para a nossa história constitucional, se a concessão de medicamentos de alto custo às pessoas com baixo poder aquisitivo restasse sobre um argumento que, ao privilegiar o direito à vida e o direito à igualdade, o fizesse pelo compromisso que funda e refunda a nossa comunidade de princípios, ou seja, de que os cidadãos de uma sociedade merecem ser tratados com igual respeito e consideração pelos seus governantes. Dessa maneira, o judiciário, ainda que contra-majoritário, pode, a despeito da vontade da maioria, garantir a minoria, que seus direitos sejam levados a sério.

Nesse aspecto, a decisão do ministro Celso de Mello pode ser considerada coerente e consistente, pois comprometida com a construção de uma história constitucional que não sacrifica o direito dos seus cidadãos em nome do interesse coletivo (argumento de política), na medida em que não tratou o direito à vida como um valor, passível de ser ponderado caso a caso. O Ministro tomou a "decisão certa", na medida em que, frente a um caso controverso como este, a melhor resposta seria aquela que fosse mais coerente, de acordo com a moral, a política e as nossas práticas jurídicas:

Entre proteger a inviolabilidade do direito à vida, que se qualifica como direito subjetivo inalienável assegurado pela própria Constituição da República (art. $5^{\circ}$, caput), ou fazer prevalecer, contra essa prerrogativa fundamental, um interesse financeiro e secundário do Estado, entendo - uma vez configurado esse dilema que razões de ordem ético-jurídica impõem ao julgador uma só e possível opção: o respeito indeclinável à vida (STF, PETMC n. 1.246/SC, rel. Min. Celso de Mello, j. em 31.1.1997.).

Entretanto, é comum que se critique que a teoria de Dworkin não pode ser aplicada em uma sociedade como a brasileira, na qual há tanta carência de direitos sociais quanto de direitos individuais. Entretanto, liberais como Dworkin entendem que os direitos sociais são extensões dos direitos individuais, isto é, a defesa de um não exclui a defesa do outro, na medida em que os direitos individuais ou negativos não têm prioridade sobre os sociais ou positivos e vice-e-versa. O reconhecimento dos direitos sociais pressupõe o dos direitos individuais. No Brasil, fica claro que é tão importante falar de direitos individuais como de direitos sociais. É justamente isso que postula nossa Constituição, conferindo inegável caráter principiológico a ambos, pois os coloca na mesma posição de direitos fundamentais. Seja como for, não é desse ponto que se trata aqui, mas de uma decisão - a suspensão da tutela antecipada n. 91 - que extrapolou os limites da argumentação judicial e adotou a forma de um argumento de policy.

Conceber os direitos como uma prática interpretativa implica na assunção de determinada atitude que seja, ao mesmo tempo, crítica e (re)construtiva. Crítica, pois não se acomoda em formulações acabadas que pretendem determinar o sentido 
do direito e dos direitos e (re)construtiva, pois todo sentido é apenas provisório e contingente. Com a democracia, apreendemos que os direitos se reinventam e, com o constitucionalismo, que eles se (auto)limitam. A partir desta tensão, o papel do direito e dos direitos em uma sociedade complexa como a brasileira é afirmar, como o faz Dworkin para a sociedade norte-americana, que só há democracia porque há constitucionalismo e vice-e-versa, em outras palavras:

Tenho argumentado contra o historicismo e o passivismo enquanto interpretações gerais da prática constitucional norte-americana. Não afirmei que cada nação deve ter uma constituição escrita com disposições abstratas sobre os direitos individuais, ou que cada uma dessas constituições deve ser interpretada por um tribunal cujos membros são escolhidos do mesmo modo que são indicados os juízes da Suprema Corte. Muitos outros arranjos são possíveis além desses que hoje permeiam a prática jurídica norte-americana, e alguns podem ser muito melhores do ponto de vista da teoria ideal (DWORKIN, 2003, p. 452).

: ARTIGO APROVADO (07/07/2009) : RECEBIDO EM 30/04/2009

NOTAS

1 Daqui para frente para nos referirmos ao Supremo Tribunal Federal utilizaremos a sigla STF.

2 Em decisão mais recente, o Ministro Celso de Mello manteve a sua postura ao impor ao Estado o dever de garantir o direito constitucional à saúde, visto que os princípios do ordenamento não podem deixar de serem cumpridos arbitrariamente nem pelo judiciário, nem pelo legislativo: “(...) DIREITO À VIDA E À SAÚDE - NECESSIDADE IMPERIOSA DE SE PRESERVAR, POR RAZÕES DE CARÁTER ÉTICO-JURÍDICO, A INTEGRIDADE DESSE DIREITO ESSENCIAL - FORNECIMENTO GRATUITO DE MEDICAMENTOS INDISPENSÁVEIS EM FAVOR DE PESSOAS CARENTES - DEVER CONSTITUCIONAL DO ESTADO (CF, ARTS. 5, "CAPUT", E 196) - PRECEDENTES (STF) ABUSO DO DIREITO DE RECORRER - IMPOSIÇÃO DE MULTA - RECURSO DE AGRAVO IMPROVIDO. O DIREITO À SAÚDE REPRESENTA CONSEQÜÊNCIA CONSTITUCIONAL INDISSOCIÁVEL DO DIREITO À VIDA. (...) DISTRIBUIÇÃO GRATUITA, A PESSOAS CARENTES, DE MEDICAMENTOS ESSENCIAIS À PRESERVAÇ̃̃O DE SUA VIDA E/OU DE SUA SAÚDE: UM DEVER CONSTITUCIONAL QUE O ESTADO NÃO PODE DEIXAR DE CUMPRIR, (...)” (STF, RE - AgR n. 399175/RS, 2ª T., rel. Min. Celso de Mello, j. em 12.12.2006, DJ de 02.02.2007).

3 Como exemplo da posição dos Tribunais inferiores quanto ao tema, podemos citar a decisão do Des. Valdemar Capeletti: “ADMINISTRATIVO. FORNECIMENTO DE MEDICAMENTOS. AÇÃO ORDINÁRIA. TUTELA ANTECIPADA. - O dever do Estado relativamente à saúde, conquanto sendo político, de nenhum modo se acha entregue à decisão política, calcada em juízos de conveniência e oportunidade, porque, tanto quanto político, também é jurídico e obriga garantia constitucional. - Reconhecido o direito do agravado ao fornecimento dos medicamentos postulados, pelo tempo em que se fizerem necessários, mantendo-se os efeitos da tutela antecipatória interpretada no sentido do pedido final e do dispositivo sentencial.” (TRF4, AG. 2005.04.10.34396-7/RS, rel. Des. Valdemar Capeletti, $4^{\circ}$ T, DJU de 26.07.2006.)

4 Sobre o tema ver ALEXY, Robert. Teoría de la argumentación jurídica: la teoría del discurso racional como teoría dela fundamentación juridi. Madrid: Centro de Estudos Constitucionais, 1997. 
066 : COMO LEVAR O SUPREMO TRIBUNAL FEDERAL A SÉRIO: SOBRE A SUSPENSÃO DE TUTELA ANTECIPADA N. 91

\section{REFERÊNCIAS BIBLIOGRÁFICAS}

ALEXY, Robert. Teoría de la argumentación jurídica: la teoría del discurso racional como teoría dela fundamentación juridica. Madrid: Centro de Estudos Constitucionais, 1997.

BARRETO, Vicente de Paulo (Coord.). Dicionário de filosofia do direito. São Leopoldo: Unisinos, 2006.

CARVALHO, Jaqueline Grossi Fernandes. Entrevista com Menelick de Carvalho Netto. Revista do Tribunal de

Contas - MG. Belo Horizonte: Revista do Tribunal de Contas/MG, v. 65, n. 4, out/dez. 2007.

CHUEIRI, Vera Karam de. Filosofia do direito e modernidade: Dworkin e a possibilidade de um discurso instituinte de direitos. Curitiba: J.M., 1995.

A dimensão jurídico - ética da razão: o liberalismo jurídico de Dworkin. In: Leonel Severo Rocha

(Org.). Paradoxos da auto - observação: percursos da teoria jurídica contemporânea. Curitiba: JM, 1997.

. A Constituição brasileira de 1988: entre constitucionalismo e democracia. Revista do Instituto de

Hermenêutica Jurídica. Porto Alegre: Instituto de Hermenêutica Jurídica, vol. 1, n. 6, 2008

Before the law: philosophy and literature. Michigan: Proquest, UMI, 2006.

CITTADINO, Gisele. Pluralismo, direito e justiça distributiva. 3. ed. Rio de Janeiro: Lúmen Júris, 2004.

DWORKIN, Ronald. Levando os direitos a sério. Trad. Nelson Boeira. São Paulo: Martins Fontes, 2002. .Taking rights seriously. Cambridge, Mass.: Harvard University Press, 1982.

O Império do direito. Tradução: Jefferson Luiz Camargo. São Paulo: Martins Fontes, 2003.

- Law's empire. London: Fontana Press, 1986.

Uma questão de princípio. Trad. Luís Carlos Borges. São Paulo: Martins Fontes, 2000

. A matter of principle. Cambridge, Mass.: Harvard University Press, 1985.

A virtude soberana: a teoria e a prática da igualdade. Trad. Jussara Simões. São Paulo: Martins Fontes, 2005. Sovereign virtue. Cambridge, Mass.; London: Harvard University Press, 2000.

GUEST, Stephen. Ronald Dworkin. Stanford: Stanford University Press, 1991.

GÜNTHER, Klaus. Teoria da argumentação no direito e na moral: justificação e aplicação. Trad. Claudio Molz. São Paulo: Landy, 2004.

HABERMAS, Jurgen. Direito e democracia: entre faticidade e validade. Trad. Flávio Beno Siebeneichler. 2. ed. Rio de Janeiro: Tempo Brasileiro, 2003. Between facts and norms. Trad. William Rehg. Cambridge, Mass.: The MIT Press, 1996.

HART, Herbert L.A. O conceito de direito. Trad. A. Ribeiro Mendes. Lisboa: Fundação Calouste Gulbenkian, 1986, p. 148 .

KOZICKI, KATYA. O positivismo jurídico de Hart e a perspectiva hermenêutica do direito. In: Leonel Severo Rocha (Org.). Paradoxos da auto-observação: percursos da teoria jurídica contemporânea. Curitiba: JM, 1997.

Vera Karam de Chueiri

Rua Conselheiro Araújo 192, apto 01 Centro - 80060-230 Curitiba - PR - Brasil vkchueiriduol.com.br

Rua Vereador Constante Pinto, nº 195, ap. 62 Bacacheri - 82.510-240 Curitiba - PR - Brasil

joannasampaiolayahoo.com.br
Doutora em filosofia pela New School for Social Research PROFESSORA DE DIREITO CONSTITUCIONAL DO PROGRAMA DE GRADUAÇÃO E PÓS-GRADUAÇÃO DA FACULDADE DE DIREITO da Universidade Federal do Paraná (UFPR)

Joanna Maria de Araújo Sampaio BACHAREL EM DIREITO PELA UnIVERSIDAdE Federal do PARANÁ (UFPR) 